\title{
MÚSICA E UNIDOCÊNCIA: PENSANDO A FORMAÇÃO E AS PRÁTICAS DE PROFESSORES DE REFERÊNCIA
}

\author{
Cláudia Ribeiro Bellochio (UFSM)* \\ Vanessa Weber (UFSM/UNISC)** \\ Zelmielen Adornes de Souza (UFSM)***
}

\begin{abstract}
RESUMO
O tema da educação musical na formação de professores não especialistas em Música, sobretudo em cursos de Pedagogia, associado aos modos de ação profissional unidocente, tem sido objeto de investigações de pesquisadores das áreas da Música e Educação, tanto no contexto nacional quanto internacional. Considera-se que a natureza do trabalho do professor que atua nos primeiros anos de escolarização é construída pela unidocência, a qual é complexa e agrega diferentes áreas para a potencialização do desenvolvimento dos estudantes. O objetivo deste artigo é discutir a unidocência e apresentar algumas compreensões com relação à formação e às práticas docentes desses professores. Para tanto, fazemos uma revisão de pesquisas que versam sobre a formação musical nos cursos de Pedagogia e, posteriormente, apresentamos parte de uma pesquisa, com base em narrativas de professoras dos anos iniciais do ensino fundamental, sobre seus modos de ser unidocente e a presença da Música em suas práticas docentes. Os resultados indicam que a educação musical está presente, com diferentes potencialidades, mas também limitações, na formação e nas práticas educativas de unidocentes. Assim, compreendemos a importância do estudo e aprofundamento das investigações, pensando na formação musical nos cursos de Pedagogia e na prática pedagógica do professor unidocente.

Palavras-chave: Educação musical. Pedagogia. Unidocência. Formação de professores.
\end{abstract}

\section{ABSTRACT \\ MUSIC AND THE GENERALIST TEACHER: ON THE EDUCATION AND PRACTICES OF ELEMENTARY TEACHERS}

The subject of musical education in generalist teacher's education, particularly in Elementary Education programs, associated to the generalist teacher's professional modes of action, has been object of research by music and education scholars, both

\footnotetext{
* Doutora em Educação pela Universidade Federal do Rio Grande do Sul (UFRGS). Docente do Magistério Superior na Universidade Federal de Santa Maria (UFSM). Bolsa de Produtividade em Pesquisa CNPQ/ Membro do Grupo de Pesquisa Formação, Ação e Pesquisa em Educação Musical (FAPEM/UFSM). E-mail: claudiabellochio@gmail.com

** Doutoranda em Educação pelo Programa de Pós-Graduação em Educação da Universidade Federal de Santa Maria (PPGE/ UFSM). Mestre em Educação pela Universidade Federal de Santa Maria (UFSM). Professora do curso de Pedagogia da Universidade de Santa Cruz do Sul (UNISC). Membro do Grupo de Pesquisa Formação, Ação e Pesquisa em Educação Musical (FAPEM/UFSM). E-mail: vanewebersm@gmail.com

*** Mestre em Educação pela Universidade Federal de Santa Maria (PPGE/UFSM). Pedagoga do Departamento de Ensino do Colégio Politécnico da Universidade Federal de Santa Maria (UFSM). Membro do Grupo de Pesquisa Formação, Ação e Pesquisa em Educação Musical (FAPEM/UFSM). E-mail: zelmielen@hotmail.com
} 
in the national and international context. We understand that nature of elementary teachers is complex and includes many areas necessary to the development of students. This paper's objective is to discuss generalist teaching and to present some insights regarding the education and practice of these teachers. To that end, we present a review of the research literature on music education in the Education Major coursework and part of an ongoing research based on the narrative of primary school teachers, on their modes of being a generalist teacher and the presence of Music in their teaching practices. The results show that musical education has been present, with different degrees of potentiality, but also with limitations, in the education and teaching practices of generalist teachers. Therefore, we understand the importance of more research regarding Music Education in Elementary Education curricula and in the practice of generalist teachers.

Keywords: Music education. Pedagogy. Elementary education. Teacher's education.

\section{RESUMEN}

\section{MUSICA Y UNIDOCENCIA: PENSANDO LA FORMACIÓN Y LAS PRÁCTICAS DE MAESTROS DE REFERENCIA}

El tema de educación musical en la formación de profesores no especialistas en música, sobretodo en los cursos de Pedagogía, asociado a los modos a acción profesionales unidocente, ha sido objeto de investigaciones de los investigadores de los campos de música y educación, tanto en el contexto nacional como internacional. Se considera que la naturaleza del trabajo del maestro es construida por la unidocencia, la cual es compleja y añade diferentes áreas para la potencialización del desarrollo de estudiantes. El objetivo de este artículo es discutir la unidocencia y presentar algunas comprensiones sobre la formación y las prácticas de estos profesores. Por lo tanto, hacemos una revisión de investigaciones sobre la formación musical en los cursos de Pedagogía y, posteriormente, presentamos parte de una investigación, basada en relatos de profesoras de la escuela primaria, sobre sus formas de ser unidocente y la presencia de la música en sus prácticas. Los resultados indican que la educación musical ha estado presente, con diferentes potencialidades, pero también limitaciones, en la formación y las prácticas educativas unidocentes. Así, entendemos la importancia y profundización de la investigación, pensando en la formación musical en los cursos de Pedagogía y en la práctica pedagógica del profesor unidocente.

Palabras clave: Educación musical. Pedagogía. Unidocencia. Formación de profesores.

\section{Formação de professores, Pedagogia e unidocência: expondo um tema}

Desde o final da última década do século $\mathrm{XX}$, no Brasil, produções bibliográficas que focalizam a formação de professores têm sido recorrentes, incluindo-se os estudos acerca da formação acadêmico-profissional de professores para os primeiros anos da educação básica. Trata-se do estudo de um campo de atuação profissional constituído pelo delineamento de um professor de referência que tem a docência orientada por modos de ser peculiares, os quais temos nomeado e entendido como unidocente/multidisciplinar/monodocente (BRZEZINSKI, 2008; MIZUKAMI et al., 2002; SACRISTAN, 2000).

A contratação de professores, em nível nacional, tem sido orientada pela LDB, Lei no 9.394/96 (BRASIL, 1996), Art. 61, a qual destaca que "pro- 
fessores habilitados em nível médio ou superior para a docência na educação infantil e nos ensinos fundamental e médio" são profissionais possíveis para atuar na educação básica escolar. Desse modo, é admitida a contratação de professores com Ensino Médio na modalidade Normal e/ou egressos de cursos de ensino superior em Pedagogia. Nosso foco expositivo, neste artigo, considerará o contexto do ensino superior, o curso de Pedagogia.

Com relação ao curso de Pedagogia, é importante lembrar que, após um longo período de discussões entre pesquisadores brasileiros e posições expressas pelas Associações Nacionais, como a Associação Nacional pela Formação dos Profissionais da Educação (ANFOPE) e a Associação Nacional de Pós-graduação e Pesquisa em Educação (ANPEd), o Conselho Nacional de Educação (CNE) aprovou e lançou, em 15 de maio de 2006, as Diretrizes Curriculares Nacionais para o Curso de Graduação em Pedagogia (DCNP), que o definem como o lócus, no ensino superior, que formará o professor de educação infantil e anos iniciais, dentre outras orientações (BRASIL, 2006). Com as Diretrizes, passa-se a ter "uma base comum nacional - formação para a docência, a extinção das habilitações, e a ampliação do campo do exercício profissional" (BRZEZINSKI, 2008, p. 219). As habilitações da Pedagogia que formavam o orientador educacional, supervisor educacional, o administrador escolar e o inspetor escolar foram extintas. A docência nos primeiros anos de escolarização, que já caracterizava a orientação formativa de alguns cursos de Pedagogia no país, há no mínimo duas décadas, passa a ser parte importante do projeto pedagógico de formação superior de professores, sendo um de seus objetivos prioritários.

É também com a orientação legal, mas não essencialmente, referente ao ensino superior, que viemos sustentando a Pedagogia como curso formador de professores e trazemos o campo da educação musical para dialogar, problematizar e entender algumas relações que têm sido construídas entre a educação musical e os professores não especialistas em Música.

Pensar a formação em Educação Musical de professores pedagogos é também problematizar a Educação como um todo. Propor a formação em música de professores não especialistas é eleger a Arte, e nesse caso em especial a música, como traço importante não só da formação dos próprios professores em formação, mas também daqueles que serão as pessoas que vão compartilhar das escolhas feitas por estes futuros professores, seus alunos. (PACHECO, 2014, p. 85).

Somada aos aspectos teóricos acerca da formação de professores e aspectos políticos que orientam as DCNP, a política educacional brasileira, com o apoio de entidades de classe e associações que se debruçam ao encaminhamento de uma formação mais humana e estética, também tem trazido outros contextos para a Música na escola de educação básica. Esses contextos fundamentam-se na alteração do Art. 26, no parágrafo $2^{\circ}$ da $\operatorname{LDB},{ }^{1}$ que dispõe: "o ensino de arte constituirá componente curricular obrigatório, nos diversos níveis da educação básica, de forma a promover o desenvolvimento cultural dos alunos" (BRASIL, 1996).

Após um movimento articulado entre músicos, educadores musicais e representantes políticos do país, foi sancionada pelo presidente da República a Lei $n^{\circ} 11.769 / 08$, que modificou o Art. 26 da LDB, acrescentando-lhe o parágrafo $6^{\circ}$, através do qual: “A música deverá ser conteúdo obrigatório, mas não exclusivo, do componente curricular de que trata o parágrafo $2^{\circ "}$ (BRASIL, 2008), ou seja, "o ensino da arte". Essa Lei sofreu modificações no ano de 2016, pela Lei $n^{\circ} 13.278$, de 02 de maio, a qual, mais uma vez, alterou a LDB, Lei no 9.394/96. Atualmente, "As artes visuais, a dança, a música e o teatro são as linguagens que constituirão o componente curricular de que trata o $\S 2^{\circ}$ deste artigo" (BRASIL, 2016a). O prazo legal aos sistemas de ensino é o de cinco anos, a partir da publicação da Lei, para que sejam realizadas as alterações necessárias.

Seja com a Lei $n^{\circ} 11.769 / 08$, seja com a atual Lei n ${ }^{\circ} 13.278 / 16$, orienta-se a presença da Música na educação básica ou, dito de outra forma, ter Música na educação infantil e nos anos iniciais do ensino fundamental também faz parte da Lei. Como os professores que atuam nesses níveis escolares são unidocentes, ou seja, organizam sua prática docente a partir das várias áreas de conhecimento,

1 Através da Lei $n^{\circ} 12.287$ (BRASIL, 2010), de 13 de julho de 2010, esse parágrafo também passou a ser acrescido do seguinte: "O ensino da arte, especialmente em suas expressões regionais, constituirá componente curricular obrigatório nos diversos níveis da educação básica, de forma a promover o desenvolvimento cultural dos alunos". 
entendemos que também estão implicados com a potencialização da Música na escola. Por suposto, existem possibilidades e limites nessa atuação (BELLOCHIO, 2000, 2002, 2007, 2008; BELLOCHIO; FIGUEIREDO, 2009), algumas das quais discutiremos ao longo deste artigo. Reenfatizamos que, muito mais do que por forças legais, a Música é uma das áreas do conhecimento que compõe um conjunto de saberes e práticas importantes ao desenvolvimento dos seres humanos. Importante porque faz parte do dia a dia da vida dos estudantes. Importante, também, porque a música pode ser criada e inventada no contexto da educação básica.

Significa, então, não à 'volta' da música e seu ensino à escola em moldes semelhantes aos que já tivemos em épocas anteriores; bem diferente disto, a construção de alternativas contemporâneas. Alternativas que ofereçam condições a crianças e jovens de tomarem contato prazeroso e efetivo com sua própria musicalidade, desenvolvê-la e vivenciá-la, mediante experiências criativas, a música em seu fazer humanamente integrador e transformador; o que significa desenvolverem seus potenciais, conhecerem-se melhor e qualificarem sua existência no mundo. Cantar e tocar, ouvir e escutar, perceber e discernir, compreender e se emocionar, transcender tempo e espaço... há muito conteúdo e significado abaixo da superfície dessas expressões, que afloram todas as vezes em que experimentamos uma relação direta e por inteiro com a música. (KATER, 2012, p. 42-43).

Salientamos, entretanto, que a relação de professores da educação infantil e dos anos iniciais do ensino fundamental com a Música não é simples e nem está resolvida do ponto de vista da formação acadêmico-profissional e tampouco da educação básica escolar.

Frente ao exposto, inicialmente discorremos sobre orientações conceituais acerca da unidocência, trazendo considerações sobre o professor de referência, a unidocência e a Música. Na sequência, apresentamos uma breve revisão de pesquisas que versam sobre a formação musical no curso de Pedagogia e finalizamos nossas reflexões com parte de resultados iniciais de uma pesquisa, com base em narrativas de professoras dos anos iniciais do ensino fundamental, sobre seus modos de ser unidocente e a presença da Música em suas práticas profissionais.

\section{Professor de referência, unidocência e Música}

No grupo de estudos e pesquisas Formação, Ação e Pesquisa em Educação Musical (FAPEM), ${ }^{2}$ da Universidade Federal de Santa Maria (UFSM), diversificam-se temáticas de pesquisa e linhas teórico-metodológicas, sendo algumas delas voltadas à investigação e compreensão do que envolve ser professor de referência, não especialista em Música, nos primeiros anos de escolarização, sendo sua ação profissional construída pela unidocência, e imbricada a essa ação, a educação musical (BELLOCHIO; GARBOSA, 2014).

Em decorrência, uma parte considerável da produção científica sobre essa temática se encontra nas pesquisas do grupo FAPEM (AHMAD, 2011; ARAÚJO, 2012; BELLOCHIO, 2000, 2015; CORREA, 2008; DALLABRIDA, 2015; FURQUIM, 2009; OESTERREICH, 2010; PACHECO, 2005; SPANAVELLO, 2005; STORGATTO, 2011; WERLE, 2010). Isso se deve à trajetória do ensino de Música nos currículos do curso de Pedagogia da UFSM, sendo um dos poucos cursos no Brasil a ter uma disciplina específica da área de Música, a qual existe oficialmente desde 1984 (OESTERREICH, 2010). Essa trajetória potencializou o olhar sobre/ para a formação musical e pedagógico-musical dos professores dos primeiros anos escolares, bem como para as práticas educativas com a Música de professores unidocentes na escola.

As pesquisas têm problematizado, de modo geral, o mundo vivido no ensino superior e na educação básica, seus desafios e possibilidades, focalizando o curso de Pedagogia, a formação continuada de professores, a relação entre estagiários do curso de Licenciatura em Música e professores de referência, o trabalho docente em sala de aula, entre outros. Desse modo, as investigações se constituem em diversidades relevantes para olhar e pensar a formação do professor, seu trabalho e sua vida, o que envolve diferentes elementos, pessoas e contextos, em constante transformação (BELLOCHIO, 2016). Com base nisso, preocupa-

2 O grupo, que tem como líder a Prof ${ }^{\mathrm{a}}$. Dr ${ }^{\mathrm{a}}$. Cláudia Ribeiro Bellochio e vice-líder a Prof ${ }^{a}$. Dr ${ }^{a}$. Luciane Wilke Freitas Garbosa, é formado por professoras do ensino superior, acadêmicos(as) de cursos de graduação, mestrado, doutorado e pós-doutorado da UFSM. 
-nos, enquanto grupo, olhar e entender as relações entre a formação e as práticas docentes, as quais se expressam através de relações que não são diretas e tampouco biunívocas, e sim relações nas quais

O papel do educador [professor] em tudo isso não é o de um técnico, de uma parteira, mas tem de ser compreendido em termos da responsabilidade pela 'vinda ao mundo' de seres únicos, singulares, em termos da responsabilidade pelo mundo como um mundo de pluralidade e diferença. (BIESTA, 2013, p. 26).

Temos nos guiado pela compreensão de que o professor de referência é "aquele com o qual os alunos permanecem a maior parte do período escolar" (BRASIL, 2010, p. 9) e por isso “[...] envolve a compreensão de um docente que mantém elo entre a vida escolar e a possibilidade de o aluno que chega na escola ter alguém que o conhecerá, de modo mais intenso, no processo de escolarização dos primeiros anos do ensino fundamental" (BELLOCHIO; SOUZA, 2017, p. 14).

O professor de referência é um profissional cuja prática constitui-se de modo unidocente. Ele organiza seu trabalho pedagógico a partir das várias áreas do conhecimento, tendo como orientação, segundo exposto nas DCNP: “ensinar Língua Portuguesa, Matemática, Ciências, História, Geografia, Artes, Educação Física, de forma interdisciplinar e adequada às diferentes fases do desenvolvimento humano" (BRASIL, 2006, p. 11).

Trata-se de um trabalho pedagógico complexo, de natureza interdisciplinar.

Desse modo, a unidocência, tomada como ação profissional e perspectiva conceitual, associa-se às formas de trabalho docente do professor que atua na Educação Infantil e nos anos iniciais do Ensino Fundamental, como professor de referência. A unidocência combina-se ao fazer cotidiano em sala de aula do professor que tem sua docência caracterizada pelo compromisso profissional de potencializar as formas de organização de conhecer das crianças, o que confere a esse profissional uma importância ímpar no contexto da educação básica, pois é o professor que mais tempo permanece em docência com seus alunos e que, assim, melhor conhece os processos de construção de conhecimentos da infância, o que é base para estruturação das áreas que movimentam as atividades curriculares nesses níveis, dentre elas a Música. (BELLOCHIO; SOUZA, 2017, p. 23-24).
Nesse sentido, o objeto de pesquisa educação musical e professores de referência (unidocente) nos é caro por sua complexidade e representação na vida escolar, por ter uma intensa relação com "a vinda ao mundo" de crianças "únicas e singulares" as quais estão vivenciando os primeiros anos da escolarização, ou seja, momentos nos quais são disparadas potencializações diversas ao desenvolvimento humano, possibilitando a construção de um mundo de pluralidades e de diferenças. Para o FAPEM, não é um tema somente do âmbito do ensino superior, mas estende-se à sua destinação, quer seja a docência na educação infantil e nos anos iniciais do ensino fundamental, quer seja em suas relações escolares como um todo. Posto isso, é fundamental pensar em sua interface com a educação musical, tendo em vista que "[...] a música como conhecimento humano tem que ser disponibilizada, tanto como apreciação quanto pelo fazer musical, para os pequenos que chegam ao mundo, aliás, eles chegam a um mundo musical, sonoro" (TERAHATA, 2012, p. 12); e, portanto, nas proposições docentes que perpassam a formação e ação profissional de professores de referência.

As pesquisas que temos realizado têm-se ancorado nessas compreensões. Entretanto, ainda que tenhamos algumas pistas, problematizações se interpõem e são atravessadas, dentre as quais: Terá esse profissional uma formação para trabalhar com Música? O que envolve a formação musical de um professor unidocente? Poderá a Pedagogia assumir a educação musical como uma de suas áreas formativas? Como a Música dialoga com o contexto da prática profissional unidocente? Como deverá ser a formação musical e pedagógico-musical de um professor não especialista em Música? O que a literatura da área de educação musical tem pensado e produzido sobre isso?

\section{Pesquisas sobre a formação musical do professor unidocente: breve revisão da literatura}

\section{Reflexões sobre a formação a partir de pesquisas do FAPEM}

Como viemos mencionando, ao pensarmos sobre a educação musical na escola de educação básica, entendemos que o professor unidocente po- 
deria propiciar uma contribuição significativa para a educação musical nos primeiros anos de escolarização. Entretanto, para que esse profissional tenha maiores possibilidades de inserir conhecimentos musicais em sua prática pedagógica é necessário que ele tenha vivenciado experiências musicais e pedagógico-musicais em sua formação. Essa necessidade formativa também é destacada por Bellochio (2014a, p. 58), quando indica que "[...] por ser um espaço/tempo de formação acadêmico-profissional de professores é que enfatizo a importância/necessidade de disciplina(s) de Educação Musical em matrizes curriculares da Pedagogia”.

A formação musical do professor de referência, muitas vezes, traz mazelas decorrentes de sua formação anterior ao curso de Pedagogia. Como vimos, o professor unidocente é responsável por orientar e mediar os aprendizados iniciais dos alunos nos vários campos do conhecimento (BRASIL, 2006) e, ao longo de sua escolarização, construiu conhecimentos sobre estas diferentes áreas porque fez disciplinas que compuseram o seu currículo. Todavia, com relação às Artes, a Música, provavelmente, não se fez presente na formação escolar da maioria desses professores. O trabalho com conteúdos musicais, os quais não foram construídos ao longo de suas vidas, torna-se então desafiante, e por que não dizer, uma dificuldade, visto que, na maioria dos casos, mesmo tendo uma bagagem de conhecimentos musicais não formais, esse professor não consegue vincular tais conhecimentos às dimensões de ensino e de aprendizagem na educação básica (CORREA, 2008; WERLE, 2010).

Em pesquisa acerca da educação musical nos cursos de Pedagogia das universidades públicas do Rio Grande do Sul, Furquim (2009) destacou que a área da Música não se encontrava no currículo da maioria dos cursos como uma disciplina específica. Com relação aos cursos que possuíam disciplinas que proporcionavam conhecimentos das linguagens artísticas, a autora percebeu a insuficiência de carga horária para a formação musical e pedagógico-musical. A pesquisa de Correa (2008) também trouxe apontamentos sobre a pouca formação musical nos cursos de Pedagogia.

A ausência de disciplinas específicas no campo das artes, especialmente em relação à música, nos cur- sos de Pedagogia, e a consequente falta de recursos e espaços destinados ao trabalho específico com a música, tende a ser fator excludente da introdução de um trabalho com música na escola mais elaborado. (CORREA, 2008, p. 97).

Tais pesquisas, na construção de seus argumentos dissertativos, discorrem sobre cursos de Pedagogia que não possuem disciplinas específicas de Música e sobre a situação de cursos nos quais essas disciplinas existem, mas são consideradas insuficientes. Tendo consciência de que a maioria dos alunos dos cursos de Pedagogia não vivenciou aulas de Música durante sua escolarização, existirão orientações para o processo de formação musical, durante a graduação, que sejam consideradas potenciais pedagógico-musicais para que esse professor insira conteúdos musicais em suas aulas?

Com relação aos objetivos da formação musical no curso de Pedagogia, as professoras unidocentes entrevistadas por Correa (2008, p. 155) apontam, como uma das necessidades formativas, a "preparação teórica e prática em música para justificar suas propostas ao se envolverem com a educação musical como área do conhecimento, dentro da escola". Observando os dados trazidos por Correa (2008), percebemos que falta a essas professoras um aprofundamento teórico específico que lhes proporcione compreender a importância da Música como área de conhecimento, para que assim possam justificar e defender a inserção de conteúdos musicais em suas práticas pedagógicas.

Ainda que defendamos que o professor unidocente também trabalhe com o ensino de Música nos anos iniciais do ensino fundamental, de forma alguma compreendemos que com isso esse profissional deva substituir o professor formado nos cursos de Licenciatura em Música. Pelo contrário, acreditamos que todas as escolas deveriam contar com um professor especialista na área em seu corpo docente. Infelizmente, essa não é a realidade de grande parte das escolas de educação básica no Brasil. No caso de escolas que tenham esse professor, seria possível que o unidocente trabalhasse com o especialista (BELLOCHIO, 2000), ampliando, dessa forma, o contato que os alunos têm com a Música e suas especificidades.

Em sua dissertação, Oesterreich (2010), além de pesquisar a história da disciplina de Música no 
curso de Pedagogia, aborda a questão do trabalho colaborativo entre professor unidocente e professor especialista em Música. A autora entende que o professor unidocente "[...] pode proporcionar trabalhos em conjunto, de forma integrada e colaborativa com o professor especialista em Música, com vistas a inserir a área no ambiente escolar de forma expressiva, promovendo um ensino musical significativo e contextualizado aos educandos" (OESTERREICH, 2010, p. 48). Para que exista esse trabalho colaborativo, porém, é essencial que o unidocente tenha, durante a sua formação, contato com conhecimentos musicais. Assim poderá compreender o trabalho realizado pelo licenciado em Música e propor formas de envolver esse trabalho em suas próprias práticas com os alunos. Consideramos importante salientar, porém, que a formação musical durante o curso de Pedagogia não garante o envolvimento do professor unidocente com a área em sua futura prática em sala de aula. Nesse sentido, retomamos o que tem nos sido caro, que é pensar quais limites e possibilidades formativas podem decorrer de disciplinas de Educação Musical durante o curso de Pedagogia, bem como de outras atividades musicais ofertadas durante o curso.

As disciplinas de educação musical na Pedagogia, muitas vezes, são o primeiro contato formal das graduandas com a educação musical. [...] Assim, apesar das disciplinas contribuírem de um modo expressivo com a ressignificação da música e com a mudança de discurso das alunas acerca da música na escola, elas não são suficientes, muitas vezes, para internalização de possibilidades musicais a serem promovidas na docência. (WERLE, 2010, p. 99-100).

Os resultados das pesquisas do grupo demonstram que as disciplinas de Educação Musical, em alguns casos, são percebidas pelas alunas/professoras unidocentes como não sendo suficientes. Entretanto, nas pesquisas de Bellochio (2000), Correa (2008) e Werle (2010) são abordadas, além dos limites, as potencialidades da formação musical durante o curso de Pedagogia. Sobre isso, Werle (2010), que pesquisou com alunas do curso de Pedagogia em período de estágio, destaca que as estudantes perceberam que tais disciplinas
[...] proporcionaram uma nova forma de compreender a música. Através delas, foi possível conhecer novos repertórios, aprender sobre seus conteúdos específicos e elaborar planos de aula para trabalhar a música na educação infantil e anos iniciais do ensino fundamental. (WERLE, 2010, p. 64).

Resultados como esse demonstram a importância de disciplinas de Educação Musical na formação do professor unidocente, apesar de todas as limitações que as mesmas possuem, visto que

[...] (re)construir concepções sobre a Educação Musical requer uma sólida formação inicial, o que exige tempo para não somente se realizarem atividades práticas, mas sobretudo para que os docentes tenham a oportunidade de interagir com estudos teóricos sobre os quais debrucem-se, dialoguem, critiquem e construam suas próprias concepções. (SPANAVELLO, 2005, p. 44).

Ao concluir esta seção, trazemos novamente alguns aspectos importantes na reflexão sobre a formação musical e pedagógico-musical, de modo curricular, ao curso de Pedagogia. Vimos que a formação musical durante a graduação não garante que a Música esteja presente nas práticas pedagógicas dos professores unidocentes atuantes nos anos iniciais do ensino fundamental, porém proporciona a esses professores o contato com os conhecimentos próprios da área, mostra possibilidades de trabalho pedagógico-musical e problematiza a unidocência e suas relações com a Música na escola. Mesmo que o período destinado às disciplinas de Educação Musical seja percebido como insuficiente para suprir demandas formativas dos acadêmicos, o fato do professor unidocente vivenciar essas disciplinas, durante a graduação, pode motivá-lo a aprofundar conhecimentos musicais e pedagógico-musicais após o ensino superior. Além disso, é importante pensarmos que mesmo com a exigência legal, nem todos os professores unidocentes desejam trabalhar com o ensino de Música. As disciplinas de Educação Musical seriam uma forma de motivá-los a inserirem a música em suas práticas pedagógicas na educação básica? De que modo se espera que ocorram essas inserções? Ter um conhecimento mais aprofundado da área mudaria a percepção e a motivação que esses professores têm em relação à Música? 


\section{Reflexões sobre as implicaç̃̃es da formação musical}

A partir da revisão de algumas pesquisas do FAPEM, vimos que muitas universidades ainda não contam com tal formação e que nas universidades que possuem disciplinas relacionadas à Educação Musical, muitos alunos, devido à falta de formação formal em Música anterior à entrada no ensino superior, as percebem como insuficientes para que se sintam seguros para trabalhar com a área. Esse sentimento de insuficiência talvez ocorra porque mesmo com o objetivo de que o professor unidocente "[...] seja responsável por todas as áreas do currículo escolar, a preparação artística, em geral, e a preparação musical, em particular, têm sido abordadas de forma superficial e insuficiente pelos cursos formadores desses profissionais" (FIGUEIREDO, 2004, p. 56).

Ampliando a exposição, nos remetemos às pesquisas nacionais e internacionais que vêm focalizando a formação musical e apresentam resultados de disciplinas de Música na formação dos unidocentes, demonstrando como essas disciplinas são percebidas pelos alunos e suas implicações para a prática docente com Música.

No contexto brasileiro, destacamos as pesquisas de Figueiredo (2004) e Aquino (2007), pesquisadores que investigaram a formação musical em cursos de Pedagogia nas regiões Sul e Centro-Oeste, respectivamente. Com relação às pesquisas internacionais, ressaltamos as investigações de pesquisadores australianos, como Gifford (1993), Welch (1995), Alter, Hays e O'Hara (2009) e Garvis e Pendergast (2010a, 2010b).

Figueiredo (2004) realizou uma pesquisa sobre a formação musical em cursos de Pedagogia em 19 universidades brasileiras.

Todos os cursos investigados oferecem pelo menos uma disciplina de artes em seu currículo que forma professores generalistas. A maioria das instituições oferece uma única disciplina para as artes, com 60 horas de duração em média, ministrada por um único professor. Em 15 das 19 instituições pesquisadas havia um único professor para o ensino de arte com a função de abordar todas as áreas artísticas. A concepção da disciplina é que as artes devem ser trabalhadas conjuntamente, o que perpetua a noção da polivalência para as artes, onde um professor deve dar conta de todos os conteúdos artísticos. Apesar de toda a discussão acumulada sobre a ineficiência da polivalência para as artes, tal discussão parece não ter atingido os cursos de pedagogia de maneira significativa. (FIGUEIREDO, 2004, p. 58).

Além do fato de vários cursos não contarem com uma disciplina de Música, outra questão preocupante levantada por Figueiredo (2004) é o fato de professores sem formação acadêmica em Artes atuarem com o ensino de Artes no curso de Pedagogia.

A formação musical de professores generalistas na maioria dos cursos de pedagogia se mostrou extremamente frágil nas instituições pesquisadas. A carga horária insuficiente e a falta de profissionais habilitados em diferentes áreas artísticas podem ser vistas como os maiores impedimentos para uma formação mais adequada dos professores generalistas. Tal formação insuficiente não permite que os professores generalistas incluam em suas práticas pedagógicas atividades significativas em termos de música e artes. (FIGUEIREDO, 2004, p. 60).

A situação apontada por Figueiredo (2004) encontra-se também em universidades de outras regiões brasileiras. Aquino (2007), ao investigar a formação musical nos cursos de Pedagogia da região Centro-Oeste, percebeu que "[...] um quadro desolador despontou: o ensino musical possui presença marginal nos currículos pesquisados. Muitas instituições sequer contemplam a Arte; outras embora a contemplem acabam por deixar de lado a música" (AQUINO, 2007, p. 105). A partir dos resultados apontados por Figueiredo (2004), Aquino (2007) e pelas pesquisas do FAPEM, percebemos que a pouca valorização dada à Arte, e especificamente à Música, é uma questão que ocorre não somente no contexto da escola de educação básica, mas também no ensino superior. Essa situação gera o que Aquino (2007, p. 107) considera como um "[...] efeito cascata: ausência da música em cursos de Pedagogia que leva ao descaso para com o trabalho na escola regular". Tendo como base tais resultados, como esperar que professores egressos da Pedagogia se preocupem com a educação musical em suas aulas?

Apesar das pesquisas mostrarem a Música ocupando um lugar periférico no currículo de cursos de Pedagogia, é importante destacar que não são 
pesquisas recentes. $\mathrm{O}$ contexto mais recente tem apontado algumas alterações na formação musical nos cursos de Pedagogia Além disso, nos últimos anos também houve a ampliação da educação a distância, com a Universidade Aberta do Brasil, possibilitando a formação musical também para alunos de cursos de Pedagogia nessa modalidade de ensino (SOUZA, 2017). Com isso, destacamos a importância da continuidade de investigações a respeito da formação musical dos professores unidocentes no contexto brasileiro.

$\mathrm{Na}$ revisão de pesquisas internacionais, também encontramos resultados semelhantes aos apontados pelas pesquisas brasileiras. Garvis e Pendergast (2010b, p. 3, tradução nossa) indicam que nos cursos de formação de professores para a educação infantil e anos iniciais "a maioria dos programas oferece muito poucas horas de formação em música, com poucas oportunidades para que conhecimentos de conteúdo e habilidades em música sejam aprendidos". Além dessa formação ser percebida como de curta duração, as pesquisas australianas mostram resultados não tão positivos com relação à percepção dos professores unidocentes sobre as disciplinas relacionadas ao ensino de música. De maneira geral, os professores unidocentes entrevistados pelos pesquisadores percebiam sua formação em Artes, e especificamente em Música, como limitada (ALTER; HAYS; O'HARA, 2009); consideravam que o trabalho desenvolvido não era relevante para o ensino na sala de aula dos anos iniciais, devido à não apresentação de métodos de ensino de Arte que pudessem ser desenvolvidos com seus alunos (WELCH, 1995); e apontavam que, ainda que percebessem um crescimento em relação à sua formação musical, não acreditavam que a formação nas disciplinas de educação musical era relevante para o cumprimento das reais necessidades de ensino relacionadas com suas salas de aula atuais, sendo que "[...] a prática de ensino não era vista como útil ou relevante em termos de prepará-los para ensinar música na escola" (GIFFORD, 1993, p. 40, tradução nossa). Garvis e Pendergast (2010a) descrevem alguns problemas, relatados pelos professores, relacionados à percepção negativa com relação às Artes durante os cursos de formação de professores:
[...] necessidade de aplicação de seus cursos de artes a um contexto de ensino; conflitos com professores/ tutores; exposição limitada na universidade para a gama de assuntos de artes; interesses conflitantes em relação à Matemática e Inglês; avaliação e pressão geral no âmbito das disciplinas de artes. (GARVIS; PENDERGAST, 2010a, p. 35, tradução nossa).

As investigações sublinham que os alunos sentem falta de uma aproximação maior do que é desenvolvido durante as disciplinas com a realidade escolar, quando se tornam professores. Além disso, destacam a necessidade de um maior tempo para a formação em Artes e o contato com métodos de ensino durante a formação. No contexto brasileiro, Figueiredo (2004, p. 60) destaca que

[...] os cursos de pedagogia precisam compreender melhor a importância das áreas artísticas na formação de pedagogos, e os profissionais das artes precisam rever práticas pedagógicas vigentes, identificando elementos que propiciem uma preparação significativa dos profissionais generalistas.

As pesquisas que abordam a percepção dos alunos sobre a formação musical e as implicações dessa formação para a prática pedagógica de professores unidocentes com a Música podem contribuir para a reflexão e construção dessa formação musical significativa para os professores formados em cursos de Pedagogia. Em uma tentativa de qualificar a formação durante o curso, Figueiredo (2004, p. 59) aponta que

[...] algumas instituições têm procurado oferecer, além das disciplinas de artes, oficinas em diferentes linguagens para ampliar a formação de seus estudantes. No entanto, essas oficinas são esporádicas e optativas, permitindo que muitos estudantes terminem seus cursos com uma formação artística superficial e insuficiente para trabalharem com segurança esses conteúdos na escola.

Tendo como referência o exposto, percebemos que a formação musical e pedagógico-musical no ensino superior - Pedagogia, e a maneira como essa formação ocorre, é um aspecto relevante e tem implicação direta nas práticas musicais que o professor de referência poderá potencializar em suas salas de aula. Consideramos que a presença da Música nas práticas do professor de referência é parte do que constitui os modos da unidocência 
na escola. Esse é o foco da pesquisa em desenvolvimento que passamos a abordar.

\section{Modos de ser unidocente e educação musical: narrativas de professoras de referência}

Pensar modos de ser unidocente se mistura à compreensão de que a relação que um professor de referência estabelece com seus alunos é um dos traços fundamentais para a potencialização de processos de construção de conhecimentos ao longo da vida. Para Di Giorgi (2010, p. 50), esses professores são "docentes que deveriam proporcionar todas as potencialidades ao pleno desenvolvimento das crianças, envolvendo dimensões afetiva, ética, estética e intelectual, por meio de ações que respeitem a dignidade e o direito das crianças".

Quando o autor ressalta que, para o pleno desenvolvimento das crianças, os professores deveriam proporcionar todas as potencialidades envolvendo diferentes dimensões do ser, refletimos sobre a importância da Música nesse processo entendendo que

A educação, seja a educação de crianças, a educação de adultos, seja a educação de outros 'recém-chegados', é afinal sempre uma intervenção na vida de alguém; uma intervenção motivada pela ideia de que tornará essa vida, de certo modo, melhor: mais completa, mas harmoniosa, mais perfeita - e talvez até mais humana. (BIESTA, 2013, p. 16, grifo do autor).
Ao ensinar, os professores afetam e são afetados por seus alunos. Suas ações docentes se traduzem em referência, intervindo nos processos formativos dos alunos e configurando seus modos de ser unidocente. Nesse sentido, professores e estudantes têm papel fundamental em suas proposições, evidentemente que associados ao projeto político-pedagógico e à comunidade escolar, que constroem e (re)significam continuamente esse espaço.

Pensando sobre isso, apresentamos parte da produção de dados de uma pesquisa ${ }^{3}$ em desenvolvimento, no grupo FAPEM, intitulada "Professores e educação musical na escola: modos de ser unidocente e pensar a música na escolarização dos anos iniciais do ensino fundamental" (BELLOCHIO, 2014b). Essa pesquisa tem como objetivo geral compreender os modos de ser unidocente trazidos em narrativas de professores de referência/pedagogos, atuantes na escola nos anos iniciais do ensino fundamental, e suas maneiras de pensar a Música/educação musical no processo de escolarização. A orientação metodológica tem como base um estudo com entrevistas narrativas. Neste texto, trazemos análises iniciais de entrevistas individuais realizadas com seis professoras dos anos iniciais do ensino fundamental, as quais são apresentadas na Tabela 1, que versam sobre alguns modos de ser professor unidocente e suas relações com a Música expressos em suas narrativas.

Tabela 1 - Informações sobre as professoras participantes da pesquisa

\begin{tabular}{|lll|}
\hline $\begin{array}{l}\text { Pseudônimo das } \\
\text { professoras }\end{array}$ & $\begin{array}{l}\text { Tempo de serviço na } \\
\text { Educação Básica }\end{array}$ & $\begin{array}{c}\text { Ano(s) escolar(es) } \\
\text { em que atuam }\end{array}$ \\
\hline Professora Ana & 2 meses & $5^{\circ}$ ano \\
\hline Professora Fátima & 6 anos & $4^{\circ}$ ano \\
\hline Professora Gina & 7 anos & $3^{\circ}$ e $4^{\circ}$ anos \\
\hline Professora Julia & 15 anos & $2^{\circ}$ ano \\
\hline Professora Neli & 18 anos & $4^{\circ}$ ano \\
\hline Professora Poliana & 20 anos & $4^{\circ}$ ano \\
\hline
\end{tabular}

Fonte: Elaborada pelo autor deste artigo com base nos dados de Bellochio (2014b). 
Ouvir e analisar as narrativas das professoras entrevistadas possibilitou-nos entender um pouco mais sobre suas relações com o mundo da docência nos anos iniciais do ensino fundamental a partir de suas memórias pessoais e profissionais. Para elas, ser unidocente

[...] é esse professor único que trabalha todas as disciplinas, digamos assim, para desenvolver as mais diversas habilidades, eu entendo como isso. $\mathrm{Na}$ verdade, a gente tem que ter um conhecimento de tudo e do todo. (PROFESSORA JULIA).

Exige bastante conhecimento, tipo ter que trabalhar essas disciplinas, porque tu estás à frente do aluno, então, tu vais ter que saber, tu estás formando eles, então, eu acho que ser professor unidocente é tu dares conta de trabalhar com todas as disciplinas. (PROFESSORA ANA).

Para mim, unidocência é quando você atinge o aluno, trabalhando com todas as disciplinas, com tudo que envolve a disciplina de uma série. [...] Mas assim é de trabalhar todos os conhecimentos que são, que dizem respeito a essa série que o aluno está frequentando... sempre se referindo aos anos inicias, porque [...] depois fica dividido por áreas de conhecimento e também por disciplinas. [...] O que é ser unidocente? É tu conseguires trabalhar com todas essas áreas de conhecimento, com todas as disciplinas com essa mesma turma. É, então, unidocente. Não é tudo junto a semana inteira, [...] é integrar essas disciplinas, o que nós chamamos depois nos anos finais de interdisciplinaridade é quando trabalha um tema, um projeto e agrega todas as disciplinas nesse mesmo tema, então seria interdisciplinar. Então, unidocente para mim é trabalhar [...] como professora unidocente com todas as disciplinas da série. (PROFESSORA POLIANA).

É o uni, é só para dizer que é uma pessoa só. $\mathrm{Na}$ verdade, a tua função é múltipla enquanto unidocente. É a função do pedagogo em si. Ela tem uma expectativa muito grande de funções que tu tens que dar conta. E muitas vezes esse uni representa [...] em determinados momentos certa solidão. Uma solidão pedagógica. Tu és unidocente, significa que tu não podes, então, conversar com outros colegas; tu não podes ter um trabalho [...] interdisciplinar, digamos assim: É um processo, até dar conta que é processo unidocente, muito só na palavra, que é tu sozinho, mas que tu precisas trabalhar em rede para conseguires dar conta da demanda que é ser unidocente. Essa parte do ser multi vai desde a questão de ter domínio, digamos assim ... do que tu tens que trabalhar. Tu saber como vai fazer isso e aonde tu vais buscar esse apoio. É assim que vejo a função unidocente. [...] Sempre correndo de um lado para o outro para dar conta daquilo que é tua função. (PROFESSORA FÁTIMA).

Eu acho que o professor é um pouquinho tudo. É professor, psicólogo, fonoaudiólogo... É tudo dentro da sala de aula. É professor de português, matemática, ciências, história. É tu e tu ali dentro. Tem a direção, mas eles não estão ali dentro contigo as quatro horas da tarde te acompanhando. Tu tens que se virar, tu tens que perceber o que teu aluno sabe e o que ele não sabe, o que ele está sentindo e o que ele não está sentindo. A gente é um pouquinho 'mix', faz tudo, isso é a unidocência. (PROFESSORA GINA).

[...] eu acho que é a visão do todo, é quase que um supervisor. Tem que... Tu não podes ter o aluno só como aprendiz, tens que ver o aluno como um ser humano que está ali, que tem sua história e que ele age assim porque ele tem um motivo para agir assim. (PROFESSORA NELI).

Nas narrativas das professoras observamos algumas compreensões semelhantes sobre o que significa ser unidocente, assim como certas particularidades e perspectivas diversas, as quais juntas complementam e configuram modos de ser unidocente. Sobre as compreensões que se aproximam nas narrativas, de certa forma, todas destacam o trabalho com diferentes áreas do conhecimento. Considerando a narrativa da professora Poliana e pensando na formação desse profissional, parece existir uma necessidade formativa de um currículo em perspectiva integrada, tendo em vista que o processo de escolarização nos primeiros anos do ensino fundamental, também possui um caráter integrado, evidenciado por ela como interdisciplinar.

A integração curricular no $1^{\circ}$ grau se apoia no regime da monodocência [...], que atribui um professor a cada grupo de alunos, e no próprio formato do currículo que, ao ordená-lo sob o código de áreas de conhecimento e de experiências obriga, de alguma forma, a se ligar a conteúdos diversos na elaboração de materiais [...] e na própria prática docente dos professores. (SACRISTAN, 2000, p. 78).

Outro ponto destacado pela professora Poliana é uma prática profissional do professor unidocente 
que tenha como foco o aluno, de modo que as escolhas feitas no planejamento e nas práticas docentes nos anos iniciais não se limitem às preferências do professor. Ao centrar o foco no aluno, sublinha-se o caráter humano que envolve o trabalho dessa professora.

[...] uma das questões que precisa tomar cuidado é não ensinar pro meu aluno só aquilo que eu gosto, né? Porque eu acho que cada professor tem um gosto mais pela linguagem, pela matemática, um peso maior pela ciência e deixam de lado a geografia ou história. Outros não valorizam ter educação física, outros não dão bola pra música, né? Outros não estão nem aí pra poesia... Então, eu acho que esse cuidado da gente ter, essa importância de um plano de curso, de fazer um planejamento, de poder atingir cada uma desses conhecimentos que as crianças têm direito a saber é importante. E aí, então, esse é um cuidado que cada professor tem que ter. A ênfase não pode ser no que eu quero. A ênfase tem que ser aquilo que o aluno precisa. Eu acho que esse olhar da gente ter o aluno como centro mesmo do nosso trabalho e não no que eu gosto, no que eu quero. $E$ isso é bem dificil porque a gente se faz professor com a nossa vida né, mas não pode se deixar afetar somente por isso. Então são coisas que eu acho... que é para eles que nós vivemos, que é pra eles que nós existimos. Ah, claro que para nós, para a gente se sentir realizado no que se faz é só vendo os alunos crescerem. É então por isso que nosso olhar inclui eles. Esse cuidado com eles. Eu acho que pra ser unidocente tu tem que ser isso. (PROFESSORA POLIANA).

Esse caráter humano também é evidenciado nas narrativas das professoras Gina e Neli, as quais sublinham a importância de uma relação humana entre professor e aluno, marcada pelo respeito e pela afetividade.

[...] acho que o papel do professor é muito bonito. Não é só vir aqui e ensinar o Português, Matemática, História e Geografia. Tem toda uma questão social, uma questão emocional, um carinho, amizade e o respeito com o aluno. Eu acho que o ser professor é envolvido com tudo isso. (PROFESSORA GINA).

[...] para gente ensinar alguém, primeiro a gente tem que cativar. Eles têm que permitir que a gente tenha acesso a eles, senão eles criam uma barreira que não vai. Porque a gente só aprende quando a gente quer aprender. Então, eu acho que a afetividade na nossa profissão é muito importante. É a gente chegar a ser amigo deles para eles permitirem que a gente transforme eles. (PROFESSORA NELI).

Biesta (2013, p. 48) destaca que "uma das principais responsabilidades educacionais é a de propiciar oportunidades para que os indivíduos venham ao mundo", o que demanda "um interesse pelos pensamentos e sentimentos de seus estudantes, permitindo que respondam de acordo com suas próprias e únicas maneiras". Assim, de modo geral, as professoras entrevistadas percebem que, no trabalho de um unidocente, a proximidade entre aluno e o professor é mais forte, a pedagogia é fundamental para criar esses laços e o professor ter uma visão mais ampla sobre o desenvolvimento do aluno em todas as áreas. Assim, esse professor torna-se referência por passar maior tempo com os alunos.

Eu acho assim, que o professor unidocente entende bem mais o aluno que um professor de área, porque ele está mais direto com o aluno, tem mais contato. O professor de área fica cinquenta minutos, vira as costas e sai, vem outro professor. Ele não tem aquela percepção integral do aluno, tem dias que o aluno está melhor, tem dia que está pior, depende do que acontece em casa, depende da matéria... Dependendo, um aluno é melhor em português, outro é melhor em matemática. E o professor unidocente, ele sabe: não, meu aluno ele tem mais dificuldades em Matemática, mas ele é muito bom na leitura e na escrita. Ejá o professor de área, ele não tem esta noção. (PROFESSORA GINA).

As professoras também narram que a unidocência acaba por assumir amplas funções e incorporar atribuições de outros profissionais, tais como psicólogos, fonoaudiólogos etc., como enfatizado na narrativa da professora Gina. Com base nisso, as entrevistadas descrevem a unidocência como sendo um "mix" (PROFESSORA GINA), que envolve ser "multi" (PROFESSORA FÁTIMA), tendo em vista a complexidade da profissão docente, a qual implica a relação e a formação de seres humanos, exigindo conhecimentos diversos que se vinculam a diferentes campos do saber. A partir disso, refletimos que "[...] a unidocência se constitui pela unidade dada a uma diversidade de conteúdos, conhecimentos, funções e atribuições presentes na docência nos anos iniciais do ensino fundamental" (BELLOCHIO; SOUZA, 2017, p. 26). 
Desse modo, buscando potencializar a formação humana dos alunos, algumas professoras mencionam desenvolver atividades musicais, trabalhando com canções, histórias sonorizadas, percussão corporal e até mesmo com o ensino de flauta doce.

Eu acredito que sim, não só a música, como a parte de artes como um todo. Mas a questão da música, eu acho que ela tem um potencial maior inicialmente, pela proximidade. É dificil de encontrar uma pessoa que não goste de trabalhar algo relacionado à música, então... Eu vejo a questão musical muito mais pra uma sensibilização e outras possibilidades culturais, assim, que as crianças podem usar, ou pelo menos proporcionar que eles conheçam isso. Então, eu vejo a parte musical mais como uma sensibilização, para eles como pessoas, como seres humanos. (PROFESSORA FÁTIMA).

Narrando sobre a presença da Música na escola em que trabalha, a professora Poliana comenta que as práticas são menores do que ela gostaria. Ela conta que tem professores que não gostam de Música e que acabam por não realizar atividades musicais com seus alunos. Contudo, esse não é o seu caso, pois a professora Poliana relata que costuma promover show de talentos em suas aulas e que adora ouvir as crianças, bem como cantar e aprender coisas novas, tais como atividades envolvendo percussão etc. (BELLOCHIO, 2016). Quando questionada sobre o que busca ensinar de Música aos seus alunos, ela expressou:

Assim, eu busco o que eles têm em comum. Passar umas mensagens positivas e provocar alegria, mostrar a alegria deles e provocar alegria nos outros. Apresentando uma música boa, uma música com qualidade e também para eles se divertirem com a música. Fazer eles gostarem, fazer aquela brincadeira com o taquinho... Eu tenho lá os taquinhos de madeira para fazer 'Escravos de Jó'. A gente trabalha com a escala de notas musicais para que eles percebam [alturas] o som do corpo, o som das coisas, o ritmo. E que eles escutem também! Não é só cantar! Que ouçam! Que ouçam alguma coisa para e pelo o gosto de ouvir! Ah... Até tem um livro de Artes que veio nesse último ano, que eu achei legal. Quando eu vi o livro de Artes eu me lembrei de ti [referindo-se à pesquisadora entrevistadora]. (PROFESSORA POLIANA).

Percebemos que Poliana valoriza e incentiva o trabalho com música em sala de aula, ainda que não possua conhecimentos musicais formais. Contudo, relata que sempre buscou aprender e se envolver com atividade musicais ao longo de sua vida. Conta que aprendeu algumas posições para tocar violão, a cantar em corais e organizar grupos musicais etc.; assim como enfatiza o quanto sua prática docente relaciona Música com outros conhecimentos, de forma interdisciplinar, mas sem utilizá-la com a função de facilitar outras aprendizagens (BELLOCHIO, 2016).

Já a professora Gina narra algumas dificuldades com relação ao trabalho musical, destacando limitações acerca do material de música recebido na escola.

Não, eles só te mandam aquele caderno gigante, com tudo ali, e deu. A gente tenta, ritmo, sonoridade, mas é bem complicado para mim, por exemplo, que não sei tocar nenhum instrumento, que não tem muita noção. Porque é bem isso que eles fazem, que a SMED faz mesmo. Manda um livro com tudo, com todos os conteúdos, e não é só eu, porque às vezes eu olho para minhas colegas e digo: 'Gurias vocês que têm mais experiência do que eu, o que é isso aqui?' 'Ah, não sei.' É bem complicado! (PROFESSORA GINA).

Apesar de se sentirem inseguras em alguns momentos em relação aos conhecimentos específicos da área, as professoras demonstram o desejo e a busca pela realização de atividades que desenvolvam um maior contato dos alunos com a Música. Sobre essa questão, a professora Neli descreve a satisfação que sente ao ver seus alunos tocando.

[...] eu acho que a música me traz assim... aconchego. Pra mim, quando eu toco flauta, não é trabalho, eu estou me divertindo com eles! Então, é uma maneira de me sentir bem e vê-los tocando, quando eles apresentam... É bem gratificante ver eles apresentando. (PROFESSORA NELI).

Nas narrativas das professoras, percebemos a vontade e a satisfação de trabalhar com a Música, apesar de dificuldades que possam sentir tanto em relação à formação musical quanto ao contexto escolar em que estão inseridas. Além disso, algumas professoras relatam a necessidade de ter um professor licenciado em Música na escola, com o qual possam desenvolver um trabalho conjunto, 
tendo em vista o desafio de trabalharem com muitas áreas de conhecimento.

Quem sabe um professor de música, que é Lei e a gente não tem. Mas eu acho que nos conteúdos em geral eu defendo a unidocência. No Português, Matemática, Ciência e Geografia, eu defendo a unidocência. (PROFESSORA GINA).

Tudo. É muita coisa para a gente saber tudo. Porque a gente passa para eles o básico que a gente sabe, mas às vezes a gente passa alguma coisa errada por não saber, peca... É o que eu acho. Ficaria tão bonito ter um professor de música... 'Ah, esta é a aula de música.' [...] Que o pedagogo ficasse junto orientando, mas com o professor de música ali do lado, ensinando direitinho como é, até as notas, tudo, até para desenvolver o potencial dos alunos. Acho que essa é a parte da escola pública também. (PROFESSORA GINA).

Eu acho que a gente deveria ter mais contato com profissionais da área, assim, para a gente desenvolver mais essa visão. (PROFESSORA NELI).

Nesse contexto, refletimos que

[...] uma ação conjunta entre unidocentes e especialistas poderá contribuir para uma melhor existência da música na escola de educação básica, já que os dois profissionais poderão trabalhar, compartilhadamente, no processo de construção da área na escola de educação básica (BELLOCHIO; GARBOSA, 2010, p. 255).

Contudo, destacamos a importância da presença da Música na formação acadêmico-profissional dos professores de referência, tendo em vista que, dessa forma, poderão ampliar suas relações musicais e pedagógico-musicais frente à área e também compreender a Música no desenvolvimento das crianças.

\section{Considerações}

Neste artigo, tivemos o objetivo de discutir alguns traços de ser professor de referência e seus modos na unidocência e apresentar algumas compreensões sobre a formação e a prática docente desses professores com relação à educação musical. Inicialmente, destacamos que o trabalho musical de unidocentes constitui parte dos processos de educação musical na escola, e se soma aos realizados por professores de música. Potencializar a formação musical e pedagógico-musical de professores unidocentes na Pedagogia, e reconhecer suas ações profissionais, amplia possibilidades do trabalho do professor de música, sustenta uma educação escolar mais articulada entre profissionais e áreas do conhecimento que promovem o desenvolvimento humano.

Destacamos que a formação com Música nos cursos de Pedagogia é um campo a que o grupo de pesquisa FAPEM tem dedicado atenção, sempre compreendendo que uma grande responsabilidade social para um professor é mediar diferentes e diversas formas de um estudante ver e ouvir o mundo. Nesse contexto, compreendemos que o professor unidocente pode fazer música na sala de aula percebendo de modo mais aguçado suas produções musicais junto aos estudantes, seja cantando, tocando, ouvindo, dentre outras possibilidades de ações com música na sala de aula.

As pesquisas revisadas apontam como resultados, e de modo geral, a ainda insuficiente, quando não nula, formação musical nos cursos de Pedagogia e a defesa de que os conhecimentos da área da Música façam parte da construção docente dos futuros pedagogos. Tendo como referência a revisão realizada, salientamos a importância da continuidade e aprofundamento das pesquisas sobre formação musical na Pedagogia, possibilitando à área maior conhecimento e compreensão do contexto mais recente de formação.

A partir dos resultados das pesquisas referenciadas na revisão, aprofundamos nossas reflexões sobre a unidocência e a educação musical trazendo análises iniciais de uma pesquisa realizada pelo FAPEM. A partir das narrativas das professoras entrevistadas, entendemos que ser professor unidocente não apresenta apenas um modo, mas sim diversos, os quais se ligam aos percursos formativos trilhados por essas professoras. Assim, quanto maiores forem as suas vivências com a Música, mais elas buscarão por formação nessa área e por promover atividades musicais aos alunos de modo a atender às necessidades formativas deles e possibilitar a vinda de seres únicos e singulares, tendo em vista que "[...] vir ao mundo não é algo que os indivíduos podem fazer sozinhos" (BIESTA, 2013, p. 47). 


\section{REFERÊNCIAS}

AHMAD, Laila Azize Souto. Música no ensino fundamental: a Lei no 11.769/08 e a situação de escolas municipais de Santa Maria. 2011. 336 f. Dissertação (Mestrado em Educação) - Universidade Federal de Santa Maria (UFSM), Santa Maria, RS, 2011.

ALTER, Frances; HAYS, Terrance; O'HARA, Rebecca. Creative Arts teaching and practice: critical reflections of primary school teachers in Australia. International Journal os Education \& the Arts, v. 10, n. 9, p. 1-21, mar. 2009.

AQUINO, Thaís Lobosque. A música na formação inicial do pedagogo: embates e contradições em cursos regulares de Pedagogia da região Centro-Oeste. 2007. 122 f. Dissertação (Mestrado em Educação) - Faculdade de Educação, Universidade Federal de Goiás (UFG), Goiânia, 2007.

ARAÚJO, Gabriela da Rós de. Formação continuada em música: reconstruindo conhecimentos musicais e pedagógico-musicais com professoras unidocentes. 2012. 104 f. Dissertação (Mestrado em Educação) - Universidade Federal de Santa Maria (UFSM), Santa Maria, RS, 2012.

BELlOCHIO, Cláudia Ribeiro. A educação musical nas séries iniciais do ensino fundamental: olhando e construindo junto às práticas cotidianas do professor. 2000. $423 \mathrm{f}$. Tese (Doutorado em Educação) - Universidade Federal do Rio Grande do Sul (UFRS), Porto Alegre, 2000.

. Escola-Licenciatura em música-pedagogia: compartilhando espaços e saberes na formação inicial de professore. Revista da ABEM, Porto Alegre, v. 7, n. 7, p. 41-49, 2002.

As necessidades formativas em educação musical: um estudo na formação inicial da Pedagogia UFSM. In: ENCONTRO REGIONAL SUL DA ASSOCIAÇÃO BRASILEIRA DE EDUCAÇÃO MUSICAL, 10., 2007, Blumenau. Anais... Blumenau: ABEM, 2007. v. 1. p. 1-8.

Educação Musical e necessidades formativas: o que dizem os professores unidocentes? In: ENCONTRO NACIONAL DA ASSOCIAÇÃO BRASILEIRA DE EDUCAÇÃO MUSICAL, 17., 2008, São Paulo. Anais... Porto Alegre: ABEM, 2008. v. 1. p. 1-7.

Educação básica, professores unidocentes e música: pensamentos em tríade. In: BELLOCHIO, Cláudia Ribeiro; GARBOSA, Luciane Wilke Freitas (Org.). Educação Musical e Pedagogia: pesquisas, escutas e ações. Campinas, SP: Mercado das Letras, 2014a. p. 47-68.

Professores e educação musical na escola: modos de ser unidocente e pensar a música na escolarização

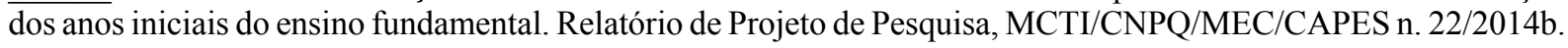

Educação musical e formação acadêmico-profissional na Pedagogia: sentidos, tensões e vicissitudes. Relatório de Pesquisa CNPQ/PQ, 2015.

Por que pensar a educação musical na formação de professores não especialistas em música? - a unidocência em foco. In: ENCONTRO REGIONAL SUL DA ASSOCIAÇÃO BRASILEIRA DE EDUCAÇÃO MUSICAL, 17., 2016, Curitiba. Anais... Curitiba: ABEM, 2016.

BELLOCHIO, Cláudia Ribeiro; FIGUEIREDO, Sérgio Luiz Ferreira de. Cai, cai balão... Entre a formação e as práticas musicais em sala de aula: discutindo algumas questões com professoras não especialistas em música. Música na Educação Básica, Porto Alegre, v. 1, n. 1, p. 36-45, 2009.

BELLOCHIO, Cláudia Ribeiro; GARBOSA, Luciane Wilke Freitas. Educação Musical na formação inicial e continuada de professores: projetos compartilhados do Laboratório de Educação Musical - LEM - UFSM/RS. Cadernos de Educação (UFPel), Pelotas, RS, v. 37, p. 217-272, 2010.

FAPEM: Formação, Ação e Pesquisa em Educação Musical. In: Pedagogia: pesquisas, escutas e ações. Campinas, SP: Mercado das Letras, 2014. p. 11-22.

BELLOCHIO, Cláudia Ribeiro; SOUZA, Zelmielen Adornes de Souza. Professor de referência e unidocência: pensando modos de ser na docência dos anos iniciais do ensino fundamental. In: BELLOCHIO, Cláudia Ribeiro (Org.). Educação musical e unidocência: pesquisas, narrativas e modos de ser do professor de referência. Porto Alegre: Sulina, 2017. p. 13-35. No prelo.

BIESTA, Gert. Para além da aprendizagem: educação democrática para um futuro humano. Belo Horizonte: Autêntica, 2013. 
BRASIL. Lei no . 9.394, de 20 de dezembro de 1996. Estabelece as diretrizes e bases da educação nacional. Diário Oficial [da] República Federativa do Brasil, Brasília, DF, v. 134, n. 248, 23 dez. 1996.

Ministério da Educação. Resolução CNE/CP nº 1, de 15 de maio de 2006. Institui Diretrizes Curriculares Nacionais para o Curso de Graduação em Pedagogia, licenciatura. Brasília, DF, 2006. Disponível em: <http://portal. mec.gov.br/cne/arquivos/pdf/rcp01_06.pdf>. Acesso em: 15 jan. 2017.

Presidência da República. Lei $\mathbf{n}^{\mathbf{0}} \mathbf{1 1 . 7 6 9}$, de 18 de agosto de 2008. Altera a Lei no 9.394, de 20 de dezembro de 1996, Lei de Diretrizes e Bases da Educação, para dispor sobre a obrigatoriedade do ensino da música na educação básica. Disponível em: <http://www.planalto.gov.br/ccivil_03/_ato2007-2010/2008/lei/111769.htm>. Acesso em: 15 jan. 2017.

Ministério da Educação. Resolução CNE/CEB no 7, de 14 de dezembro de 2010. Fixa Diretrizes Curriculares Nacionais para o Ensino Fundamental de 9 (nove) anos. Brasília, DF, 2010. Disponível em: <http://portal. mec.gov.br/dmdocuments/rceb007_10.pdf>. Acesso em: 15 jan. 2017.

. Presidência da República. Lei no 12.287, de 13 de julho de 2010. Altera a Lei no 9.394, de 20 de dezembro $\overline{\text { de } 1996}$, que estabelece as diretrizes e bases da educação nacional, no tocante ao ensino da arte. Disponível em: $<$ http://www.planalto.gov.br/ccivil_03/_ato2007-2010/2010/lei/112287.htm>. Acesso em: 15 jan. 2017.

. Presidência da República. Lei $\mathbf{n}^{\mathbf{0}} \mathbf{1 3 . 2 7 8}$, de 02 de maio de 2016. Altera o $\S 6^{\circ}$ do art. 26 da Lei $n^{\circ} .9 .394$, de 20 de dezembro de 1996, que fixa as diretrizes e bases da educação nacional, referente ao ensino da arte. Brasília, DF, 2016a. Disponível em: <http://www.planalto.gov.br/ccivil_03/_Ato2015-2018/2016/Lei/L13278.htm>. Acesso em: 15 jan. 2017.

Ministério da Educação. Resolução CNE/CEB no 2, de 10 de maio de 2016. Define Diretrizes Nacionais para a operacionalização do ensino de Música na Educação Básica. Brasília, DF, 2016b. Disponível em: <http://portal. mec.gov.br/index.php?option $=$ com_docman \&view=download\&alias=40721-rceb002-16-pdf\&category_slug=maio2016-pdf\&Itemid=30192> . Acesso em: 15 jan. 2017.

BRZEZINSKI, Iria. Políticas contemporâneas de formação de professores para os anos iniciais do ensino fundamental. Educação \& Sociedade, Campinas, SP, v. 29, n. 105, p. 1139-1166, set./dez. 2008.

CORREA, Aruna Noal. "Programa LEM: tocar e cantar": um estudo acerca de sua inserção no processo músico-formativo de unidocentes da Pedagogia/UFSM. 2008. 175 f. Dissertação (Mestrado em Educação) - Universidade Federal de Santa Maria (UFSM), Santa Maria, RS, 2008.

DALLABRIDA, Iara Cadore. Sentidos da Educação Musical na formação acadêmico-profissional de pedagogos. 2015. 155 f. Dissertação (Mestrado em Educação) - Universidade Federal de Santa Maria (UFSM), Santa Maria, RS, 2015.

DI GIORGI, Cristiano Amaral Garboggini. Et al. Necessidades formativas de professores de redes municipais: contribuições para a formação de professores crítico-reflexivo. São Paulo: Editora UNESP, 2010.

FIGUEIREDO, Sérgio Luiz Ferreira de. A preparação musical de professores generalistas no Brasil. Revista da ABEM, Porto Alegre, v. 11, p. 55-61, set. 2004.

FURQUIM, Alexandra Silva dos Santos. A formação musical de professores em cursos de Pedagogia: um estudo das universidades públicas do RS. 2009. 172 f. Dissertação (Mestrado em Educação) - Universidade Federal de Santa Maria (UFSM), Santa Maria, RS, 2009.

GARVIS, Susanne; PENDERGAST, Donna. Middle years teachers' past experiences of the arts: Implications for teacher education. Australian Journal of Music Education, n. 2, p. 28-40, 2010a. 1-22, $2010 \mathrm{~b}$.

Supporting novice teachers of the arts. International Journal of Education \& the Arts, v. 11, n. 8, p.

GIFFORD, Edward. The musical training of primary teachers: old problems, new insights and possible solutions. British Journal of Music Education, v. 10, n. 1, p. 33-46, 1993.

KATER, Carlos. Por que a música na escola? Algumas reflexões. In: JORDÃO, Gisele. Et al. (Org.). A Música na escola. São Paulo: Allucci \& Associados e Comunicações, 2012. p. 42-45. 
MIZUKAMI, Maria da Graça Nicoletti. Et al. Escola e aprendizagem da docência: processos de investigação e formação. São Carlos: EDUUFSCar, 2002.

OESTERREICH, Frankiele. A história da disciplina de Música no curso de Pedagogia da UFSM (1984-2008). 2010. 168 f. Dissertação (Mestrado em Educação) - Universidade Federal de Santa Maria (UFSM), Santa Maria, RS, 2010.

PACHECO, Eduardo Guedes. Educação musical na educação infantil: uma investigação-ação na formação e nas práticas das professoras. 2005. 118 f. Dissertação (Mestrado em Educação) - Universidade Federal de Santa Maria (UFSM), Santa Maria, RS, 2005.

. Outras escutas e fazeres musicais na Pedagogia. In: BELLOCHIO, Cláudia Ribeiro; GARBOSA, Luciane Wilke Freitas (Org.). Educação Musical e Pedagogia: pesquisas, escutas e ações. Campinas, SP: Mercado das Letras, 2014. p. 69-88.

SACRISTÁN, José Gimeno. O currículo: uma reflexão sobre a prática. Porto Alegre: Artmed, 2000.

SOUZA, Zelmielen Adornes de. A formação de professores em cursos de Pedagogia vinculados à Universidade Aberta do Brasil: unidocência e música. In: BELLOCHIO, Cláudia Ribeiro (Org.). Educação musical e unidocência: pesquisas, narrativas e modos de ser do professor de referência. Porto Alegre: Sulina, 2017. p. 193-215. No prelo.

SPANAVELLO, Caroline Silveira. A educação musical nas práticas de professores unidocentes: um estudo com egressos da UFSM. 2005. 128 f. Dissertação (Mestrado em Educação) - Universidade Federal de Santa Maria (UFSM), Santa Maria, RS, 2005.

STORGATTO, Sabrina Silveira Spanavello. Educação infantil e educação musical: um estudo com pedagogas. 2011. 108 f. Dissertação (Mestrado em Educação) - Universidade Federal de Santa Maria (UFSM), Santa Maria, RS, 2011.

TERAHATA, Adriana Miritello. Música na escola: uma experiência de (com) fiar. In: JORDÃO, Gisele. Et al. (Org.). A Música na Escola. São Paulo: Allucci \& Associados e Comunicações, 2012. p. 11-13.

WELCH, Ann. The self-efficacy of primary teachers in art education. Issues in Educational Research, v. 5, n. 1, p. 71-84, 1995.

WERLE, Kelly. A música no estágio supervisionado da Pedagogia: uma pesquisa com estagiárias da UFSM. 2010. 128 f. Dissertação (Mestrado em Educação) - Universidade Federal de Santa Maria (UFSM), Santa Maria, RS, 2010. 